\title{
Reaching out for scientific legacy: how to define authorship in academic publishing
}

\author{
Sven Thatje ${ }^{1}$
}

Received: 14 January 2016 / Accepted: 17 January 2016 / Published online: 23 January 2016

(C) Springer-Verlag Berlin Heidelberg 2016

Scientists devote their careers to the search for new discoveries, which turn into public knowledge once published as a scientific article or as an academic book. This exciting curiosity-driven search for knowledge enthuses most scientists and often occupies an exceptionally large part of a scientist's life. There are now many ways of publicising scientific discoveries, ranging from the print media to electronic publishing such as video documentary or voice podcast, all of which seek to preserve knowledge beyond human lifetime. Still, the principal way of preserving scientific discoveries for the future is the scientific article published in peerreviewed a scientific journal (Kronick, 1990; Riisgård, 2000; Thatje, 2010). For the sake of this essay, I will hereafter refer to the peer reviewed scientific article as the "paper".

What is a scientific legacy? The reputation of a scientist is based on the quality of a paper bearing the scientist's name and its impact on the respective subject area in which the paper is published. The number of papers - and their quality - published by a scientist helps building academic reputation and influences a peer's professional career. Scientific legacy describes the circumstance when a scientist's work and name remains recognised beyond lifetime if not for generations to come. It is often the body of many published works that is of legacy building nature. Consequently, a "name on a paper", as such, contributes to a scientist's potential to building legacy. Therefore, scientific legacy is about future generations of scientists recognising the contributions of their pre-

Sven Thatje

nawi@soton.ac.uk

1 Ocean and Earth Science, National Oceanography Centre, University of Southampton, European Way, Southampton SO14 3ZH, UK decessors. A good, if not groundbreaking, paper influences a research area for many years to come if not decades, and a scientist's dream is an idea-driven discovery, which governs academia well beyond human lifetime. In brief, authorship of an article declares ownership and is a claim of potential legacy.

We publish the results of research for various reasons: for the joy of it, to inform peers, for the advancement of science and society, as well as to build reputation and legacy. "Publish or perish" is another phrase governing a scientist's life, and especially that of the young scientist; presenting a long list of scientific papers in most areas of research is mandatory and influences a scientist's future as an academic or researcher.

Building reputation precedes leaving a legacy. We have seen a steep increase in publishing activities in recent decades, as science is an important driver of the developments of both economy and society. Most countries increasingly invest into a vast array of research reflecting on each country's developmental state, which has led to the number of scientists increase globally. Many areas of research develop rapidly e.g. the medical sciences, leading to unprecedented advances benefitting society. As a result, scientists from many disciplines tend to publish more papers than ever before, the reasons for which are diverse. There are many types of scientific papers (e.g. raging from short Communications to Original article formats) and the list of authors on a paper tends to be longer than what it used to be in most areas of research. The single author paper is, overall, rather rare these days, and also because research has become widely inter-disciplinary.

In summary, scientists mainly contribute to papers as coauthors rather than be the lead author. The number of authors on a paper is often driven by the impact factor (or quality) of the journal in which the article is published. Journals that have a high impact factor, which is based on the mean number of citations each article received (Riisgård, 2000; Thatje, 2010), 
tend to have greater influence on directing a research area. Authorship of any such article is therefore more desirable.

Given the diverse nature surrounding the publication of research, it is of importance to periodically revisit the criteria that "justify names on papers". Ownership of research outcomes and ideas is often at risk where e.g. academic hierarchy, funding pressure, and limited job security dominate the research environment. Here, I wish to share my very personal thoughts on this subject, which are the result of several years of experience as the editor of The Science of Nature as well as a published scientist. These "rules of thumb of publishing" may serve as guidance and for further discussion. They should be of use to any area of academia, such as for peers as well as to funding agencies and employers, and area of publishing, not only within the natural sciences.

Single author papers constitute a minor proportion to the body of published scholarly work today. The single author paper is the most desirable publication in most if not all areas of academia. The situation is getting more complicated where several peers contributed to publishable research, and consequently giving each author's contribution justice can be rather difficult. However, a few simple and clear recommendations do apply when defining authorship.

All authors of a paper must be able to present the contents of this research in detail. This should be of the quality of an oral presentation (talk) given at a science conference or as in a postgraduate (e.g. PhD) viva. This involves the discussion of content-related questions or within a public context such as media enquiries.

There are four types of authorship; the principal, also known as the first or lead author, the co-author, the senior author, and the communicating author. The most desirable position is that of the lead author, the principal authority with overall responsibility for the paper. The lead author wrote most if not all of the paper, with contributions from the coauthors. In most cases, the lead author is also responsible for managing and submitting the manuscript to the journal, including revision of the manuscript following peer review. The lead author is the main driver behind the piece of research including generating the idea(s), planning and conducting the research, analyses, and the write-up of the study for publication. The lead author certainly must be the originator of the idea, unless the idea was presented by the senior author, e.g. when supervising a research student. In many cases, the lead author also takes the position of the communicating author, to whom any paper related correspondence should be sent to. Alternatively, the communicating author is often found associated with the senior author (and is then identified as the same) and the senior author, if present, is then found in last position in a list of authors. The exact position of the senior author however, may vary and according to science culture of respective country and or case-by-case, and as indicated. The senior author often is a head of lab or research group or research grant lead or a principal $\mathrm{PhD}$ supervisor. However, the principal criteria of authorship, as outlined earlier, do also apply for the senior authorship. Where there are two peers authoring a paper, it is generally assumed that both peers contributed equally to any aspect of the paper or represent student and supervisor/senior author.

Difficulties in justifying an authorship arise when there are more than two authors; papers with approximately one to three authors tend to be easy to deal with; this can be the case of collaboration of established peers or rather often these days, a postgraduate student as lead and the involved (co)-supervisors as co-authors. In such case, the authorship to each peer's build of reputation is rather obvious. Justifying the position of a coauthor's name in a long list of authors can be much more difficult. Papers with 5 to 10 or even up to 50 authors (or more!) are not uncommon these days. Such "consortia" or "community" papers do often reflect on the type of science involved, e.g. the use of large infrastructure and consortiafunded research or the increased need for multi-disciplinary approaches. Valuing differences in any co-author's contribution in such case of multi-authorship is largely impossible. However, identifying the lead and the senior as well as communicating authors is of priority. Further, indistinguishable contributions of co-authorship are often made clear by listing peers' names in alphabetical order. Where equal contributions of authors apply, a footnote can be placed. This can be important in case where two PhD students or early career scientists are disadvantages by not figuring both as the lead author and despite having contributed equally to joint research.

There is no doubt that the average number of "names on papers" has increased in recent years. As stated before, there are numerous reasons justifying this development. However, the basic criteria of authorship do always apply! Again, longer lists of authors automatically imply that the contribution of each co-author is close to being indistinguishable. Where there are more important contributions of the individual coauthor to be underlined, the alphabetical order of listing authors may be abandoned, and a numerical order, and according to significance in contribution, may be preferred. Peer pressure can be high when developing a list of authors. Especially early career scientists can feel pressurised to succeed in their professional careers.

I have personally come under the impression that names on papers are not always justified. It is therefore desirable that scientists take clear responsibility for ideas and the resulting papers. Too often legacy is not built for those who deserve it but others who are demanding to be part of the publication; the responsibility for such development however is with all authors. Undoubtedly, funding research alone does not justify an authorship. Journal editors often favour longer lists of authors perhaps because such articles attract more (self)citations in the short run, positively affecting journal citation rates and therefore 
journal impact (Leimu and Koricheva 2005, Engqvist and Frommen, 2008).

Personally, I would like to see a development toward an increased awareness of what an authorship really means, and how important it is for building reputation and legacy. Based on my experience, it appears to me that we have largely forgotten about the role of Acknowledgements in publishing. Today, these are mainly used to acknowledge funding sources and technical support. Sometimes, word counts and article layout restrictions do not even allow for any acknowledgements these days. Where the basic authorship criteria are not fulfilled, alternatively being recognised in a paper's acknowledgements should again be seen as recognition and an indicator of a valuable contribution, which however, does not deserve authorship.

To conclude, the ways we publish and how we value authorships has changed in recent times. Re-visiting this defining issue is therefore desirable, and timely. It is the lead and senior authorships that stand out and build a scientist's reputation. Such papers should be considered in particular when seeking to employ early (and late) career scientist. This collection of thoughts should provide guidance only and is not meant to be exhaustive. The definition of authorship, in most cases however, is straightforward and courtesy authorship must be avoided. It is up to us as scientists to show integrity and honesty when publishing, to self-govern and regulate through principles of fairness. In a world in which 'publish or perish' has become our motto, these values have been eroded, though they must be maintained.

\section{References}

Engqvist L, Frommen JG (2008) The $h$-index and self-citations. Trends Ecol Evolut 23:250-252

Kronick DA (1990) Peer review in 18th-century scientific journalism. JAMA 263:1321-1329

Leimu R, Koricheva J (2005) What determines the citation frequency of ecological papers? Trends Ecol Evolut 20:28-32

Riisgård HU (2000) The peer-review system: time for re-assessment? Mar Ecol Prog Ser 192:305-313

Thatje S (2010) The multiple faces of journal peer review. Naturwissenschaften 97:237-239 